\title{
Periodic lateralized epileptiform discharges (PLEDs) in herpetic encephalitis
}

\section{Descargas periódicas lateralizadas na encefalite herpética}

William Alves Martins ${ }^{1}$, André Palmini²

An 86-year-old male presented with confusion, fever and tonicclonic seizures. CSF analysis showed lymphocytic pleocytosis and high protein count, leading to initiation of acyclovir. EEG revealed PLEDs in the left hemisphere (figure 1C) and MRI demonstrated left hippocampal and insular hyperintensities (figure 1A, 1B). Herpes simplex virus (HSV) encephalitis was confirmed by PCR.

PLEDs represent periodic sharp discharges lateralized to one hemisphere usually due to acute neuronal injury ${ }^{1,2}$.
Since not all patients present seizures, the acronym LPDs (Lateralized Periodic Discharges) may be more accurate ${ }^{3}$. Besides encephalitis, several etiologies produce PLEDs, including stroke, metabolic disarrangements, brain tumors, intracranial hemorrhage, anoxic encephalopathy, among others $^{1,2}$. Nevertheless, HSV encephalitis should always be considered and CSF studies obtained in the appropriate clinical scenario ${ }^{4}$.
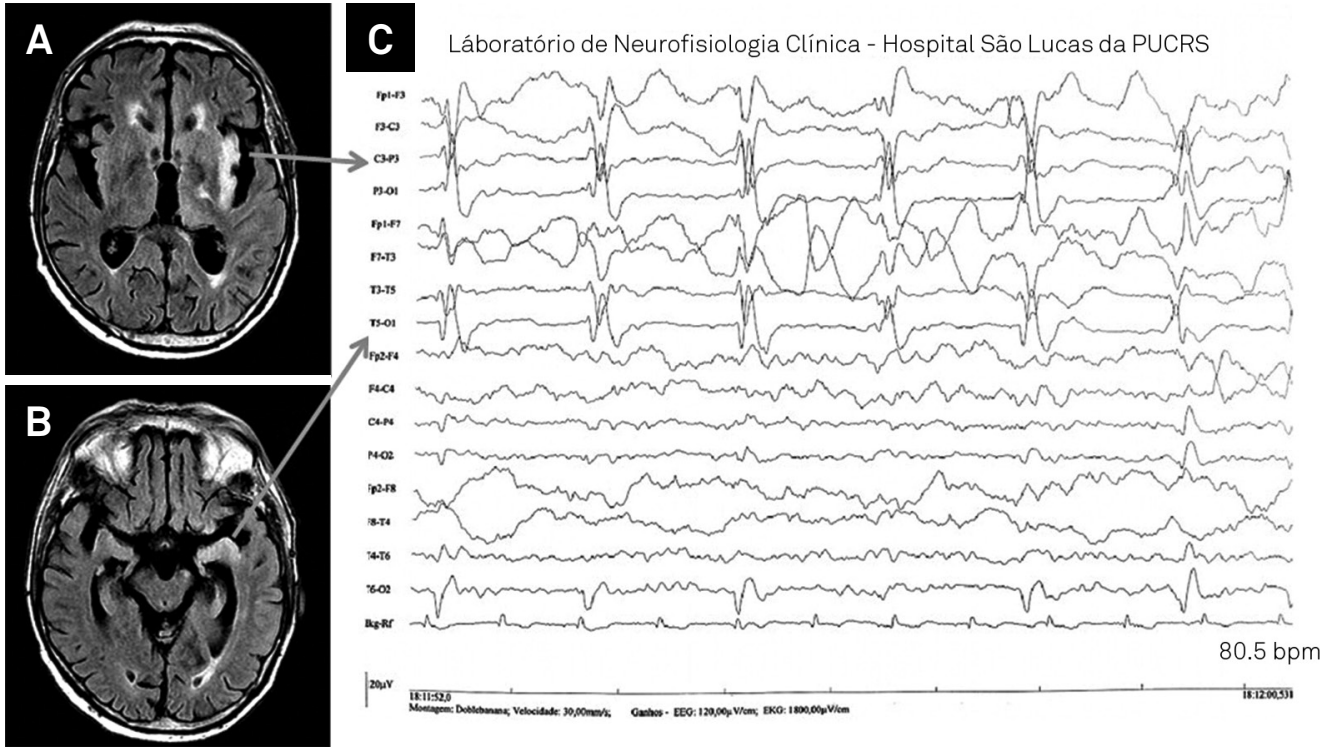

Figure. (A, B) Brain MRI; axial FLAIR sequence showing hyperintensities in the insular cortex and parahippocampal gyrus, respectively; (C) EEG demonstrating unilateral and focal sharp wave complexes that appear periodically in the left hemisphere, as the electrographic reflection of the HSV lesion (arrow).

\section{References}

1. Fitzpatrick W, Lowry N. PLEDs: clinical correlates. Can J Neurol Sci. 2007;34(4):443-50. doi:10.1017/S0317167100007332

2. Andraus ME, Andraus CF, Alves-Leon SV. Periodic EEG patterns: importance of their recognition and clinical significance. Arq Neuropsiquiatr. 2012;70(2):145-51. doi:10.1590/S0004-282X2012000200014
3. Hirsch LJ, La Roche SM, Gaspard N, Gerard E, et al. American Clinical Neurophysiology Society's Standardized Critical Care EEG Terminology: 2012 version. J Clin Neurophysiol 2013;30(1):1-27. doi:10.1097/WNP.0b013e3182784729

4. Rigamonti A, Lauria G, Mantero V, Salmaggi A. A case of late herpes simplex encephalitis relapse.J Clin Virol. 2013;58(1):269-70. doi:10.1016/j.jcv.2013.05.010

\footnotetext{
'Pontifícia Universidade Católica do Rio Grande do Sul, Hospital São Lucas, Departamento de Neurologia, Porto Alegre RS, Brazil;

${ }^{2}$ Pontifícia Universidade Católica do Rio Grande do Sul, Faculdade de Medicina, Departamento de Medicina Interna / Neurologia, Porto Alegre RS, Brazil. Correspondence: William Alves Martins; Serviço de Neurologia, Hospital São Lucas da PUCRS; Avenida Ipiranga, 6690; 90610-000 Porto Alegre RS, Brasil; E-mail:walvesm.br@gmail.com

Conflict of interest: There is no conflict of interest to declare.
}

Received 21 May 2015; Received in final form 29 June 2015; Accepted 24 July 2015. 